\title{
Fathers and Family Leave Policies: What Public Policy Can Do to Support Families
}

\author{
Alison Koslowski and Margaret O'Brien
}

"In a rapidly changing world, we will continue witnessing the growing momentum and recognition of the importance of men for gender equality, reconciling work-family life and impacting the future of their children" United Nations (2011)

\section{Types of Family Leave Available to Fathers}

The first global form of paid leave from employment was introduced in 1919 under the auspices of the International Labour Organization's Maternity Protection Convention (ILO 2014). Female focused, this measure was concerned with the health and safety of employed women just before and after childbirth. Subsequently, the late twentieth and early twenty-first centuries have witnessed an expansion of various forms of leave for men and women as managing work-life balance has become more difficult especially as more mothers return to paid employment in their child's first year (Moss and Deven 2015; World Bank 2018). Across the world, many countries have witnessed a deepened role for governments and employers in developing parental leave and other family leave policies, extending their duration and increasing the payment level, for fathers as well as mothers.

In this context, infant care is no longer purely a private family matter as employed parents attempt to accommodate 24/7 infant care within a 24/7 globalised working

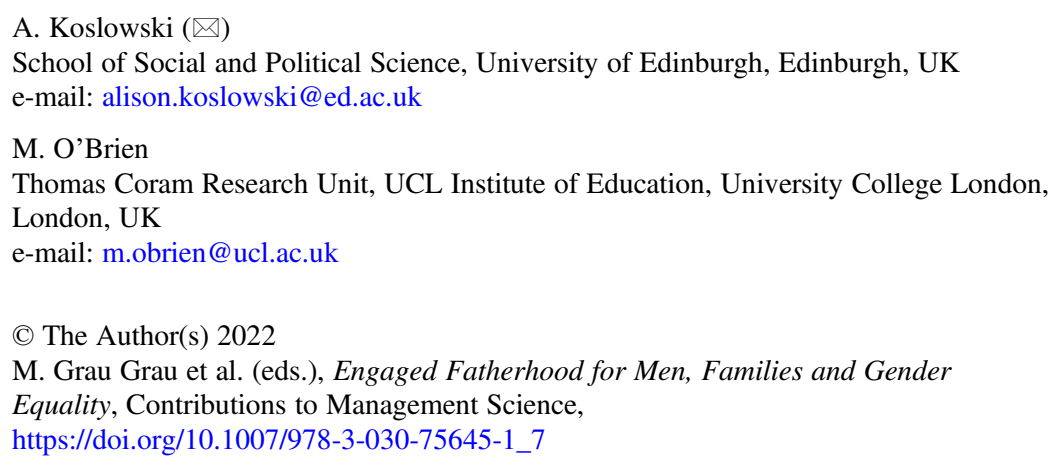


environment, involving a trade-off between the time spent on infant care and the time spent in the labour market, in the context of maintaining household financial security. At a macro level, a country's family leave regime is an important facilitating setting for achieving a sustainable work-life arrangement for financial wellbeing and family care.

Working parents across countries are entitled to a range of family leave types, the most common being maternity leave, paternity leave, parental leave, and leave to care for children who are ill. Maternity leave is leave generally available to birth mothers only, with other provision available to adoptive parents. Paternity leave is generally available to fathers only (or in some cases a same sex co-parent), usually to be taken soon after the birth of a child, and intended to enable the father to spend time with his partner, new child, and older children. In some countries, parental leave and paternity leave are synonymous. Parental leave is generally intended to give both parents an equal opportunity to spend time caring for a young child. Where available, leave to care for children who are ill would typically be available to both mothers and fathers (Bartel et al. 2018; Blum et al. 2018). Some countries aim for an almost gender-neutral leave policy overall (e.g., Sweden), with most of the leave available designated as parental leave. Other countries have a family leave system that clearly presumes the mother as a primary carer (e.g., Ireland).

Paternity leave and father-targeted parental leave schemes are expanding rapidly, across the world. Parental leave is a period of longer leave available to either parent, usually after maternity or paternity leave finishes, ranging from months to 3 years, and often, but not always, unpaid. Its provision has been found in 66 countries surveyed by ILO, mostly in developed economies, Eastern Europe, and Asia but only paid in 36, most generously in the Nordic countries. Although Sweden was the first country (in 1974) to introduce parental leave open to fathers as well as mothers, Norway was the first country (in 1993) to reserve 4 weeks of well-paid parental leave exclusively for fathers -- the non-transferable "daddy month" (Eydal et al. 2015; see also Kvande's chapter in this volume).

By 2014, the International Labour Organisation (ILO) found a statutory right to paternity leave in 79 of 167 countries, paid in 71 of the cases (ILO 2014). While a global minimum ILO standard on duration of maternity leave exists - 14 weeks, met by $53 \%$ of countries - no such standard exists for paternity leave, which globally ranges from 1 day to periods over 2 weeks. Company or government payment ranges from strong compensation, as found in Finland with 9 days at $70 \%$ of earnings to a minimal flat rate coverage as in the UK (Koslowski et al. 2016).

Leave policies provide job protection for a period of time so that a worker can be available to care for a dependent, and after this period of time, return to employment with the same employer. They can also include an element of wage replacement during this period (Ray et al. 2010). Seen as a key instrument for maintaining the presence of mothers in the labour market (Pronzato 2009; Ciccia and Verloo 2012; Dearing 2016), they are increasingly also seen as a key instrument for increasing the opportunities for fathers to spend more time caring for their young children (O'Brien 2009; Caracciolo di Torella 2014). In addition to supporting gender equality, leave policies can be seen as important policy instruments for supporting child health and 
well-being, maternal and paternal health and well-being, fertility rates, and various labour market outcomes such as reduced gender pay gaps (Kamerman and Moss 2009; Andersen 2018; Moss et al. 2019).

Leave can be unpaid, paid at a low flat rate similar to social assistance, or paid as a form of (usually approximate) wage replacement. Leave paid at a level that approximates wage replacement, is associated with increased uptake by all parents, but in particular by fathers (Pull and Vogt 2010; Ray et al. 2010; Lapuerta et al. 2011). Sometimes a nominal wage replacement system becomes similar to a low flat rate if ceilings are set too low or are not uprated over time.

Family leave policies can be categorised as either "equality-impeding," "equalityenabling," or as actively "equality-promoting" policies (Brighouse and Wright 2008). As discussed in the following chapter by Kvande, an individual entitlement is equality-promoting, whereas an individual entitlement with a transferable or family entitlement is equality-enabling, and a mother-only leave is equalityimpeding. Leave can be available for both parents at the same time, or require them to be the primary carer for this period of leave. Evidence suggests that such immediate and simultaneous father involvement such as that facilitated by paternity leave is relevant to later gender equality outcomes such as female labour market participation (Farré and Gonzalez 2017). However, evidence also suggests that fathers taking leave alone on parental leave is correlated with more gender equal sharing of childcare throughout the life course (O'Brien and Wall 2017).

Across the world paid leave from employment policies continue to evolve. Their design is responsive to new cultural, economic, and political issues as well as early influences from health and social insurance and post-war, welfare regime path dependencies.

\section{Policy Design and Leave Use by Fathers}

In some countries, men's behaviour has been receptive to public policies developed to extend their engagement with infants. Key ingredients which enhance utilization appear to be high-income replacement combined with designated father-targeted or reserved schemes rates. Evidence shows that blocks of time which are labelled "daddy days" or "father's quota" are attractive to men and their partners (Eydal et al. 2015). Designs with low-income replacement or based on maternal transfer, both features of the UK's additional paternity leave and its successor, Shared Parental Leave, are known not to encourage paternal uptake.

Since the late 1990s, strategies to enhance the visibility of fathers' entitlements to parental leave have accelerated, particularly in Europe. There has been experimentation with a range of policy instruments, based on incentive, penalty, and even compulsion. Part of the policy innovation has involved a form of re-branding where periods of leave time within individual or family entitlements have become reserved for fathers or father-targeted (sometimes referred to as a "father's quota"). Through the reconfiguration, fathers' access to a period of parental leave, previously implicit, 
within an individual gender neutral entitlement, becomes explicit. The group includes the well-established father-sensitive regimes embedded in the majority, but not all, of the Nordic countries, and the enhanced schemes come from countries as diverse as Germany, Portugal, Spain, and Slovenia.

Within Nordic countries, one of the most innovative father-targeted leave entitlements so far developed, in terms of combined time (3 months) and economic compensation (80\% of prior salary) is to be found in Iceland (Einarsdóttir and Pétursdóttir 2007). In 2000, the Icelandic government introduced a total of 9 months paid post-birth leave (to be taken in the first 18 months) organized into three parts: 3 months for mothers (non-transferable), 3 months for fathers (non-transferable) and 3 months which could be transferred between parents as they choose. In addition there is 13 weeks unpaid parental leave available each year for each parent. The Bill Maternity, Paternity and Parental Leave was passed by the Icelandic government in 2000, following several years' deliberation about men's societal role and gender equality, including a government committee on the "Gender Role of Men" (Eydal and Gíslason 2008).

The Iceland $3+3+3$ month model has significantly shifted male behaviour in a relatively short period of time. By 2006, over $90 \%$ of Icelandic fathers took parental leave. Gíslason (2007: 15) notes: "Probably, there have never been more Icelandic fathers active in caring for their children than there are today." Kolbeinn et al. (2008: 153) describe how the normative pattern is for Icelandic men to take most of their dedicated days but typically not to utilise the shared component: "You may well be regarded as weird if you don't use the paternity leave, but the same does not hold for using the shared entitlement." However, leave taking by fathers declined following the 2009 economic crisis, in particular those (higher earners) most hit by the implementation of a ceiling on the flat rate payment (Júlíusdóttir et al. 2018).

In the same decade, a radical break in family policy to create an incentive for fathers to take leave was introduced in Germany against a leave policy background which supported mothers to stay out of the labour market for 3 years after the birth of a child (Erler 2009). A new highly paid 2 months, "Elterngeld," was added to a shorter 12-month parental leave period. The reform concentrated high payment onto a shorter 12-month parental leave period, with an extra 2 months of high payment if fathers take 2 months of leave. The proportion of fathers taking leave more than tripled from $3.5 \%$ in the last quarter of 2006 to $13.7 \%$ in the second quarter of 2008 and has risen incrementally since (Blum et al. 2016).

In general, take up of leave increases as household income increases. This is in part linked to eligibility to leave being higher for those on steady (non-precarious) incomes, as picked up by Ratele in this volume. In the UK, for example, not all workers qualify for leave entitlements, due to being self-employed or not having a certain kind of employment contract. In addition, some fathers may be entitled to enhanced leave entitlements as a result of their employer offering extra-statutory occupational benefits, or linked to collective agreements. In such cases, leave uptake maybe facilitated by this top-up in provision.

In summary, fathers' access to individual and paid entitlement is strongly associated with increased take up of the leave (e.g., Haas and Rostgaard 2011; Duvander 
and Johansson 2012), though this design needs to be complemented by sustained political work and cultural change. Other incentives include the couple being eligible for an extended duration of leave if fathers take a certain amount of leave (e.g., as is the case in Austria, Croatia, France, Germany, Italy, and Portugal). It is also worth mentioning that successful leave systems are integrated with public childcare systems. For example, in Denmark, Finland, Germany, Slovenia and Sweden, the maximum duration of leave available to parents dovetails with the provision of publically subsidised childcare, so that there is no childcare gap for parents to have to fill.

\section{Impact of Fathers on Leave}

Whilst the study of fathers on leave has been of interest to researchers now for some decades (e.g., Haas 1992), empirical enquiry into the specific personal and family experiences and impact of maternal, paternal, and paternity leave is still relatively undeveloped. Macht explores in her chapter in this volume the dynamics of fatherchild emotional wellbeing. There is still surprisingly little empirical research on what parents "do" during parental leave, and even less specifically on what fathers "do", (Seward et al. 2006; Haas and Hwang 2008). As such, understanding the processes by which parental leave may operate to promote or hinder gender equity or child and family well-being are still unclear. In part, this is linked to a lack of data on parental leave use.

In addition, in attempting to understand the impact of parental leave policies there are important macro- and micro-level methodological considerations. At a macro level, parental leave is a black box of diverse arrangements, which vary both within and between countries despite common nomenclatures. As mentioned above, eligibility criteria also vary; although, in general, they tend to exclude insecure and informal workers. Also, in attempting to understand the specific impact of parental leave it is important to contextualize parental leave as part of societal level public investment.

In most countries, public investment in paid leave policies is often highly associated with more general public spending on family benefits as a proportion of GDP (Adema and Ali 2015). As such, claims from macro-level studies of impact have been academically controversial, with pathways of influence difficult to disentangle, particularly as any gains can be linked to prior characteristics of fathers (gender egalitarian and child-oriented) rather than the policy itself. Methodological issues, for example about sample selectivity, are also relevant for micro-level analyses, although qualitative research has the advantage of fine-tuned dimensional sampling not always available for large-scale administrative or survey data sets.

Where impact research does exist the focus has been mainly on the effects of maternity leave provision with several studies showing child health benefits in, for instance, immunization uptake and employment retention (Tanaka 2005; Han et al. 
2009). Positive health gains for children are maximized when the maternity leave is paid, provided in a job-secure context, and with a duration of at least 10 weeks.

In terms of fathers and leave, the logic has been that giving fathers the opportunity to spend more time at home through leave after childbirth should result in greater involvement in domestic life and childcare. More studies on fathers taking leave have been published over last decade spanning both comparative and within country policy analysis, particularly concerning implementation and impact at a macro-level (e.g., Nepomnyaschy and Waldfogel 2007; Huerta et al. 2013; Kotsadam and Finseraas 2011; Rege and Solli 2010; Bünning 2015).

The Nordic countries and Germany have provided fertile ground for "before and after" studies of impact at a country level (Ekberg et al. 2005; Duvander and Johansson 2012; Schober 2014; Bünning 2015). The natural experiment paradigm, which has framed many of these studies, has produced evidence of greater engagement of fathers in the care of children after policy reforms, in comparison with fathers who do not take leave. For instance, Kotsadam and Finseraas (2011) found that men whose last child was born in the year after Norway's father quota introduction in 1993 reported $11 \%$ lower levels of conflict over household division of labour and were 50\% more likely to share in clothes washing than men whose last child was born just before the reform. However, there has been some concern that greater engagement by fathers who have taken leave may be short-lived rather than long-term and so have a weak impact on the gendering of care. Indeed, German longitudinal analysis by Schober (2014) suggested that fathers increased their participation in childcare only temporarily during the first year after taking parental leave, but subsequent research has suggested sustained longer term effects up until the third year of the child's life (Bünning 2015; Reimer et al. 2015).

Notably, Reimer et al.'s (2015) study also found a large effect of paid parental leave taken alone by the father. In particular, an observed relationship between fathers' use of leave and their time for childcare only persisted when at least one leave month was taken alone by the fathers: an important selection criterion for this book's qualitative sample. Both Bünning (2015)and Reimer et al.'s (2015) studies were able to use nationally representative German panel data sets (German SocioEconomic Panel and Families in Germany) which include items on duration and whether leave is taken alone or with a partner. Also, the data sets allow the same fathers to be tracked before and after they take parental leave which enables exploration of selection effects.

Other country level natural experiments have assessed "duration" effects of fathers' leave on a wide range of outcomes. In a further Norwegian case, it has been found that 4 weeks' exposure to the leave quota during a child's first year was associated with a 1-3\% drop in fathers' earnings over the next 5 years (Rege and Solli 2010). In an another study of duration and fathers' engagement in childcare, research in Australia has found that taking some leave ( 2 or 4 weeks) increased the likelihood of fathers engaging in sole care at week-ends when the child was older (4-9 months) (Hosking et al. 2010). Notably, studies are emerging on child outcomes in families where fathers do not take leave in countries where it is expected that they do; for instance, Flacking et al. (2010) found that Swedish infants whose 
fathers did not take family leave in the first year were significantly less likely to be breast fed at 2- and 6-months.

Although the body of macro-level research is still emergent, it does suggest that fathers' as well as mothers' leave taking has direct as well as indirect influences on infants, family, and work life. Moreover, there are indications that leave taking alone by fathers may be especially salient in priming subsequent greater engagement in the care of infants. Earlier qualitative studies, primarily in Nordic countries, have suggested that being home alone sensitizes or enhances fathers' awareness of infant life "slow time" (Brandth and Kvande 2002). A recent set of cross-national case studies of fathers taking leave alone (O'Brien and Wall 2017) has extended these observations into a wider set of country contexts.

\section{A Good Quality of Infant Life}

Leave policies are instruments for realising children's rights to both their parents' time and care (Haas and Hwang 1999). Infant life has not traditionally been considered the province of social policy, possibly because of an historic gendered assumption (but an enduring one-see chapter by Borgkvist) that only mothers can provide the permitting circumstances. In the field of parental leave policies, the focus has not so much been on the state of infancy per se but on the parenting or care processes perceived as necessary for infant life.

In terms of classic father involvement constructs in the developmental psychology literature, leave available for fathers can be conceptualised as a way to enhancing attachment by potentiating paternal availability and interaction with infants and young children (Lamb et al. 1987). But specification of the dimensions of a good quality of life for an infant is fraught with political dilemmas, economic considerations, and, of course, relates to the models of optimal infant development dominant in any one culture at a particular historical juncture. As Waldfogel (2006: 180) states: "The tensions between respecting choice, promoting quality, and supporting employment are higher in the first few years of life than at any other period."

Contemporary hallmarks of "a good enough" infancy depend to some extent on cultural factors and the theoretical models of psychologists or sociologists. Psychologists tend to research the personal characteristics of the parents in providing the care environment, such as their parenting style, whereas sociologists pay more attention to resource and community influences on child development. An ecological-parental capital approach (Pleck 2007) requires a multi-layered and multi-dimensional framework, attempting to incorporate governmental, community, family, and individual levels for understanding infancy.

In the ecological context of early childhood and parental employment, the quality of life which infants experience, is made up of a complex set of processes and resources (some of which are explored by Macht in this volume). The daily life of the infant is organized around regular feeding on 6-8 (or more) occasions in a $24 \mathrm{~h}$ cycle, holding, soothing, diaper changing, bathing, dressing as well as sociable 
interaction, in between regular phases of infant sleeping. In this highly dependent phase of childhood the infant needs at least one carer (not necessarily the same person, although cultural norms vary) to be in close physical proximity. A century of psychological research evidence shows that the nature of adult care (in particular its sensitivity, stability, and attentiveness) fosters infant sociability although there is not a linear association between parental time availability and the quality of emergent human relationships (Cabrera and Tamis-LeMonda 2013). At a more distal level, the infant needs economic care for material resources. In essence an adequate quality of infant life, as discussed in Yogman's chapter in this volume, requires both economic and emotional investment.

\section{Supporting Fathers in the Workplace to Take Leave}

Far fewer eligible fathers take leave, in contrast to eligible mothers (Blum et al. 2018). Clearly then, new mothers and fathers have a very different experience in how they harmonise their work and their family responsibilities. Consider your own workplace, it is likely that you can quickly identify the leave-taking norms and that they will be different for mothers and fathers. This is discussed further in the following chapters by Bueno and $\mathrm{Oh}$ and by Borgkvist. While many organisations have programmes to support new mothers-offering them mentoring, back-to-work schemes and maternity replacement cover-this support intent is typically not available to new fathers.

Fathers often report feeling worried and even embarrassed to use offered leave entitlements (Koslowski and Kadar-Satat 2019; Moran and Koslowski 2019). Fathers are worried about what it might mean for their career prospects if they go against what is normal in their workplace (Rudman and Mescher 2013; Tanquerel and Grau-Grau 2020). A number of policies can help with this, including making sure fathers have adequate cover for their job responsibilities whilst on leave, and insuring that individual line managers support a father's efforts to combine work and family life (including being aware of who is a father of an infant). Fathers also need time from work to attend antenatal appointments.

Employers who are not offering paid family leave may be choosing not to do so because they worry that it could be too expensive. Research suggests that costs may balance out because of the boost in staff engagement and retention (see also chapter by Macht). Increasingly, companies with higher participation in programmes designed to support working fathers have higher employee retention and job satisfaction (Appelbaum and Milkman 2011). The good news is that employers should experience a double benefit from supporting fathers in the workplace. In addition to attracting and retaining talented fathers, they also create opportunities for mothers. As working fatherhood becomes normalised, women are less often penalised for the ways they seek to combine work and family. Because of this, firms with strong policies and cultures supporting working parents should see their gender pay gaps lessen. 
Low-income fathers are even less likely to take meaningful time off, feeling unpaid or reduced-pay time off might adversely impact their family's finances. In the absence of well-paid family leave, fathers are likely instead to take paid vacation time, therefore taking less leave to spend time with their children than they would be legally entitled to.

\section{Practical Recommendations}

The world of work and family life has transformed since the ILO's Maternity Protection Convention in 1919. As well as support for employed mothers, paid paternity leave and father targeted parental leave schemes are now important measures for parents of very young children in their daily negotiation of care, time, and money. While governments, organisations, and civil societal actors are indeed attempting to fit fathers into work-family polices the "cost" of male care can hinder innovation especially in uncertain economic times.

Unchallenged maternalism is commonplace, and so this gender gap in leave provision and take up is more socially acceptable than in many other parts of social life (such as education or the gender pay gap). Despite this, "Fathers undertaking a more active role in caregiving is likely to be one of the most significant social developments of the twenty-first century" (International Labour Organization 2014: 1).

More research is needed to understand maternal and paternal policies in unison, as what is available to mothers and fathers affects how caring is shared by parents. In particular, the interaction of maternity and paternity leave arrangements and experiences requires further scrutiny. We know that dual-earner couples negotiate parental leave use in part depending on both partners' job characteristics. Similarly, more mixed methods research programmes, combining qualitative and quantitative designs, are required in order to explore underlying familial and work-place cultural processes. Bueno and Oh consider this couple dimension across different country contexts in their chapter in this volume.

Key Recommendations for:

- Policy makers wishing to increase the proportion of fathers taking leave would be to consider the success of reforms in Germany and Iceland, as presented earlier, and ensure that there are clear incentives to families for fathers to take leave. Key ingredients which enhance leave utilisation are high-income replacement and the presence of an individual entitlement and a non-transferable component. Branding matters: Father-targeted reserved schemes such as "daddy days" are effective.

- Organizations should examine and challenge their gendered cultural practices around take up by fathers at all levels: CEO, supervisors, and peers. Fathers are parents as well as employees. Men's behaviour is very receptive to workplace culture and norms about what makes a good worker and a good father. 
- Fathers themselves: Given the growing evidence base that early father involvement matters for child development and couple wellbeing, be bold, be pioneers, take the leave you are entitled to!

\section{References}

Adema W, Ali N (2015) Recent changes in family outcomes and policies in OECD countries: the impact of the economic crisis. Community Work Fam 18(2):145-166

Andersen SH (2018) Paternity leave and the motherhood penalty: new causal evidence. J Marriage Fam 80:1125-1143

Appelbaum E, Milkman R (2011) Paid family leave pays off in California. Harv Bus Rev. https:// hbr.org/2011/01/paid-family-leave-pays-off-in

Bartel AP, Rossin-Slater M, Ruhm CJ, Stearns J, Waldfogel J (2018) Paid family leave, fathers' leave-taking, and leave-sharing in dual-earner households. J Policy Anal Manage 37(1):10-37

Blum S, Erler D, Reimer T (2016) Germany country note. In: Koslowski A, Blum S, Moss P (eds) International review of leave policies and research 2016. http://www.leavenetwork.org/lp_and_ r_reports/

Blum S, Koslowski A, Macht A, Moss P (2018) International review of leave policies and research 2018. https://www.leavenetwork.org/fileadmin/user_upload/k_leavenetwork/annual_reviews/ Leave_Review_2018.pdf

Brandth B, Kvande E (2002) Reflexive fathers: negotiating parental leave and working life. Gend Work Organ 9(2):186-203

Brighouse H, Wright EO (2008) Strong gender egalitarianism. Polit Soc 36(3):360-372

Bünning M (2015) What happens after the 'daddy months'? Fathers' involvement in paid work, childcare, and housework after taking parental leave in Germany. Eur Sociol Rev 31 (6):738-748. https://doi.org/10.1093/esr/jcv072

Cabrera NJ, Tamis-LeMonda CS (2013) Handbook of father involvement: multidisciplinary perspectives. Routledge, New York

Caracciolo di Torella E (2014) Brave new fathers for a brave new world? Fathers as caregivers in an evolving European Union. Eur Law J 20(1):88-106

Ciccia R, Verloo M (2012) Parental leave regulations and the persistence of the male breadwinner model: using fuzzy-set ideal type analysis to assess gender equality in an enlarged Europe. J Eur Soc Policy 22(5):507-528

Dearing H (2016) Gender equality in the division of work: how to assess European leave policies regarding their compliance with an ideal leave model. J Eur Soc Policy 26(3):234-247

Duvander A-Z, Johansson M (2012) What are the effects of reforms promoting fathers' parental leave use? J Eur Soc Policy 22(3):319-330

Einarsdóttir T, Pétursdóttir GM (2007) The Iceland report. In: Moss P, Wall K (eds) International review of leave policies and related research 2007 employment relations research series no. 80. Department for Business Enterprise and Regulatory Reform (BERR), London, pp 179-186. https://www.leavenetwork.org/fileadmin/user_upload/k_leavenetwork/annual_reviews/2007_ annual_report.pdf

Ekberg J, Eriksson R, Friebel G (2005) Parental leave: a policy evaluation of the Swedish "DaddyMonth" reform. IZA, Bonn. http://ftp.iza.org/dp1617.pdf

Erler (2009) Germany: taking a nordic turn? In: Kamerman SB, Moss P (eds) The politics of parental leave policies: children, gender, parenting and the labour market. Policy Press, Bristol, pp 119-130

Eydal GB, Gíslason IV (2008) Paid parental leave in Iceland-history and context. In: Eydal GB, Gíslason IV (eds) Equal rights to earn and care_parental leave in Iceland. Félagsvísindastofnun Háskóla Íslands, Reykjavík 
Eydal GB, Gíslason IV, Rostgaard T, Brandth B, Duvander A-Z, Lammi-Taskula J (2015) Trends in parental leave in the nordic countries: has the forward march of gender equality halted? Community Work Fam 18(2):167-181

Farré L, Gonzalez L (2017) The effects of paternity leave on fertility and labor market outcomes. Institute of Labor Economics (IZA) discussion paper no. 10865. https://www.iza.org/ publications/dp/10865/the-effects-of-paternity-leave-on-fertility-and-labor-market-outcomes

Flacking R, Dykes F, Ewald U (2010) The influence of fathers' socioeconomic status and paternity leave on breastfeeding duration: a population-based cohort study. Scandinavian J Public Health 38(4):337-343

Gíslason IV (2007) Parental leave in iceland bringing the fathers in. Developments in the wake of new legislation in 2000. Centre for gender equality, ministry of social affairs

Haas L (1992) Equal parenthood and social policy: a study of parental leave in Sweden. State University of New York Press, Albany

Haas L, Hwang P (1999) Parental leave in Sweden. In: Moss P, Deven F (eds) Parental leave: progress or pitfall? Research and policy issues in Europe, vol 35. NIDI/CGBS Publications, The Hague, pp 45-68

Haas L, Hwang P (2008) The impact of taking parental leave on fathers' participation in childcare and relationships with children: lessons from Sweden. Community Work Fam 11(1):85-104

Haas L, Rostgaard T (2011) Fathers' rights to paid parental leave in the Nordic countries: consequences for the gendered division of leave. Community Work Fam 14(2):177-195

Han W-J, Ruhm C, Waldfogel J (2009) Parental leave policies and parents' employment and leavetaking. J Policy Anal Manage 23(1):29-54

Hosking A, Whitehouse G, Baxter J (2010) Duration of leave and resident fathers' involvement in infant care in Australia. J Marriage Fam 72(5):1301-1316

Huerta MdC, Adema W, Baxter J, Han W-J, Lausten M, Lee RH, Waldfogel J (2013) Fathers' leave, fathers' involvement and child development: are they related? Evidence from four OECD countries. OECD social, employment and migration working papers, no 140. https://doi.org/10. $1787 / 5 \mathrm{k} 4 \mathrm{dlw} 9 \mathrm{w} 6 \mathrm{czq}-\mathrm{en}$

ILO (International Labour Organization) (2014) Maternity and paternity at work: law and practice across the world. ILO, Geneva

Júlíusdóttir Ó, Rafnsdóttir GL, Einarsdóttir P (2018) Top managers and the gendered interplay of organizations and family life: the case of Iceland. Gend Manage 33(8):602-622

Kamerman SB, Moss P (eds) (2009) The politics of parental leave policies: children, gender, parenting and the labour market. Policy Press, Bristol

Kolbeinn S, Eydal GB, Gíslason IV (2008) Summary and conclusions. In: Eydal GB, Gíslason IV (eds) Equal rights to earn and care-parental leave in Iceland. Félagsvísindastofnun Háskóla Íslands, Reykjavík, pp 97-121

Koslowski A, Kadar-Satat G (2019) Fathers at work: explaining the gaps between entitlement to leave and uptake. Community Work Fam 22(2):129-145

Koslowski A, Blum S, Moss P (2016) International review of leave policies and research 2016. https://www.leavenetwork.org/fileadmin/user_upload/k_leavenetwork/annual_reviews/2016_ Full_draft_20_July.pdf

Kotsadam A, Finseraas H (2011) The state intervenes in the battle of the sexes: causal effects of paternity leave. Soc Sci Res 40(4):1611-1622

Lamb ME, Pleck J, Charnov EL, Levine J (1987) A biosocial perspective on paternal behavior and involvement. In: Lancaster JB, Altmann J, Rossi AS, Sherrod LR (eds) Parenting across the lifespan: biosocial dimensions. Aldine de Gruyter, Hawthorne, pp 111-142

Lapuerta I, Baizán P, González M (2011) Individual and institutional constraints: an analysis of parental leave use and duration in Spain. Popul Res Policy Rev 30(2):185-210. https://doi.org/ 10.1007/s11113-010-9185-y

Moran J, Koslowski A (2019) Making use of work-family balance entitlements: how to support fathers with combining employment and caregiving. Community Work Fam 22(1):111-128

Moss P, Deven F (2015) Leave policies in challenging times: reviewing the decade 2004-2014. Community Work Fam 18(2):137-144. https://doi.org/10.1080/13668803.2015.1021094 
Moss P, Duvander A-Z, Koslowski A (2019) Parental leave and beyond. Policy Press, Bristol

Nepomnyaschy L, Waldfogel J (2007) Paternity leave and fathers' involvement with their young children. Community Work Fam 10(4):427-453

O'Brien M (2009) Fathers, parental leave policies and infant quality of life: international perspectives and policy impact. Ann Am Acad Pol Soc Sci 624(1):190-213

O'Brien M, Wall K (eds) (2017) Comparative perspectives on work-life balance and gender equality: fathers on leave alone. Springer International Publishing, Cham

Pleck JH (2007) Why could father involvement benefit children? Theoretical perspectives. Appl Dev Sci 11(4):196-203

Pronzato C (2009) Return to work after childbirth: does parental leave matter in Europe? Rev Econ Househ 7(4):341-360

Pull K, Vogt A-C (2010) Much ado about nothing? The effects of the German parental leave reform. Soziale Welt-Zeitschrift Fur Sozialwissenschaftliche Forschung Und Praxis 61(2):121-137

Ray RR, Gornick JC, Schmitt J (2010) Who cares? Assessing generosity and gender equality in parental leave policy designs in 21 countries. J Eur Soc Policy 20(3):196-216

Rege M, Solli I (2010) The impact of paternity leave on long-term father involvement. University of Stavanger, Stavanger

Reimer T, Warnholtz L, Pfau-Effinger B (2015) Daddy months' as a sustainable policy? Discerning the long-term influence of a new parental leave legislation in Germany on fathers' engagement in childcare. Paper presented at workshop "fathers' involvement in the life course" Berlin, September 3 and 4, 2015

Rudman LA, Mescher K (2013) Penalizing men who request a family leave: is flexibility stigma a femininity stigma? J Soc Issues 69(2):322-340

Schober PS (2014) Parental leave and domestic work of mothers and fathers. A longitudinal study of two reforms in west Germany. J Soc Policy 43(2):351-372

Seward RR, Yeatts DE, Zottarelli LK, Fletcher RG (2006) Fathers taking parental leave and their involvement with children. Community Work Fam 9(1):1-9

Tanaka S (2005) Parental Leaves and child health across OECD countries. Econ J 115(501):F7-F28

Tanquerel S, Grau-Grau M (2020) Unmasking work-family balance barriers and strategies among working fathers in the workplace. Organization 27(5):680-700. https://doi.org/10.1177/ 1350508419838692

United Nations (2011) Men in families and family policy in a changing world. UN, New York. http://social.un.org/index/Family/Publications.aspx

Waldfogel J (2006) What children need? Harvard University Press, Cambridge

World Bank (2018) Women, business and the law report. International Bank for Reconstruction and Development-The World Bank, Washington, DC. http://wbl.worldbank.org/

Open Access This chapter is licensed under the terms of the Creative Commons Attribution 4.0 International License (http://creativecommons.org/licenses/by/4.0/), which permits use, sharing, adaptation, distribution and reproduction in any medium or format, as long as you give appropriate credit to the original author(s) and the source, provide a link to the Creative Commons license and indicate if changes were made.

The images or other third party material in this chapter are included in the chapter's Creative Commons license, unless indicated otherwise in a credit line to the material. If material is not included in the chapter's Creative Commons license and your intended use is not permitted by statutory regulation or exceeds the permitted use, you will need to obtain permission directly from the copyright holder.

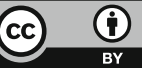

